\title{
Hovercraft, Controlled using Android App
}

\author{
Clinton A R ${ }^{1}$, Delvin Lazar ${ }^{2}$, Sarath $K^{3} M^{3}$, Shibin $K K^{4}$, Chitra S Gopi ${ }^{5}$, Nasheeda V $\mathbf{P}^{6}$ \\ UG Scholar, Electronics and Communication, IES College of Engineering, Thrissur, India ${ }^{1,2,3,4,5}$
}

Asst. Professor, Electronics and Communication, IES College of Engineering, Thrissur, India ${ }^{6}$

\begin{abstract}
The principle extent of this anticipate is to build up a remote innovation based air cushion vehicle framework controlled utilizing android. An air cushion vehicle, otherwise called an air-pad vehicle or ACV, is a specialty equipped for going over area, water, mud or ice and different surfaces. Air cushion vehicle are crossover vessels worked by a pilot as an air ship instead of a skipper as a marine vessel. It is presently utilized all through the world as particular transports in a fiasco alleviation, coastguard, military and review applications and additionally for game or traveler administration. Large forms have been utilized to transport several individuals and vehicles over the English Channel, whilst others have military applications used to transport tanks, troopers and vast gear in threatening situations and landscape A hovercraft is a non wheeled vehicle that can hover over land as well as water easily using high powered fans and aerodynamic design. We here propose an advanced hovercraft that uses high rpm motors interfaced with an avr family microntroller to achieve desired functionality. The motor below hovercraft rotates at a very high RPM that allows it to generate a force enough to make it hover on the surface thus reducing the friction below it to minimum. Then we use the motor propeller mounted behind it to push the hovercraft in forward direction. Now we also need to use a servo motor attached to the hovercraft rudder that helps the hovercraft to move in desired directions by bending the air at accurate angles. The system works collectively to hover while continuously managing servo as well as propeller motor to drive the hovercraft as desired. Now to control the hovercraft we here use an android application. The android application sends movement commands to the hovercraft circuit. The circuit consists of an Bluetooth receiver to receive and process these commands. The commands received by receiver are now processed by the microcontroller and it then operates all three motors accordingly as desired by the user.
\end{abstract}

Keywords: Keywords: Rudder, propeller, hovercraft controlled using android, thrust, ACV.

\section{INTRODUCTION}

An air cushion vehicle is an exceptional sort of vehicle that proceeds onward a pad of air. The lifting movement is controlled by a fan or fans so that an air crevice can be framed. Such partition between the base of the air cushion vehicle and the ground gives a movement stage, on which the rubbing power between the air cushion vehicle and the ground diminishes to a little sum.

Since an air cushion vehicle does not have wheels, the forward movement is made through the driving activity, which is created by the utilization of an impetus fan and/or an arrangement of fans. These impelling fans send let some circulation into of the back of the air cushion vehicle to deliver a push power, which advances the air cushion vehicle. The accompanying two pictures are from a site outlining the utilization of air cushion vehicle as a vehicle to achieve a mission of exchanging military vehicles over the water to a desert zone.

Hovercrafts work on the two main principles of lift and propulsion. Lift is an important factor because it is that which allows the craft to ride on a cushion of air. This process begins by directing airflow under the craft. In order to accumulate the air under the air cushion, a skirt is required. A fan is used to move the air for propulsion. Hovercrafts have minimal contact with the ground.

The common skirt is known as a bag skirt. The skirt that we have is used is made up of polythene. It covers the bottom of the base and has holes in it to for air to escape and push the craft off the ground. Each part of the skirt inflates independently which makes troubleshoot much easier and improves stability. The more stable the skirt is, the slower the hovercraft will move

\section{BLOCK DIAGRAM}

The block diagram explains the principle parts or functions of the system. The system consists of an micro controller Atmega 328 and this consist as a major part of hovercraft. An android application is used here for controlling the hovercraft, Bluetooth receiver is also used here,2 High rpm motors and one rudder motor is also included in the circuit 
International Journal of Innovative Research in Electrical, Electronics, Instrumentation and Control Engineering

ISO 3297:2007 Certified

Vol. 5, Issue 5, May 2017
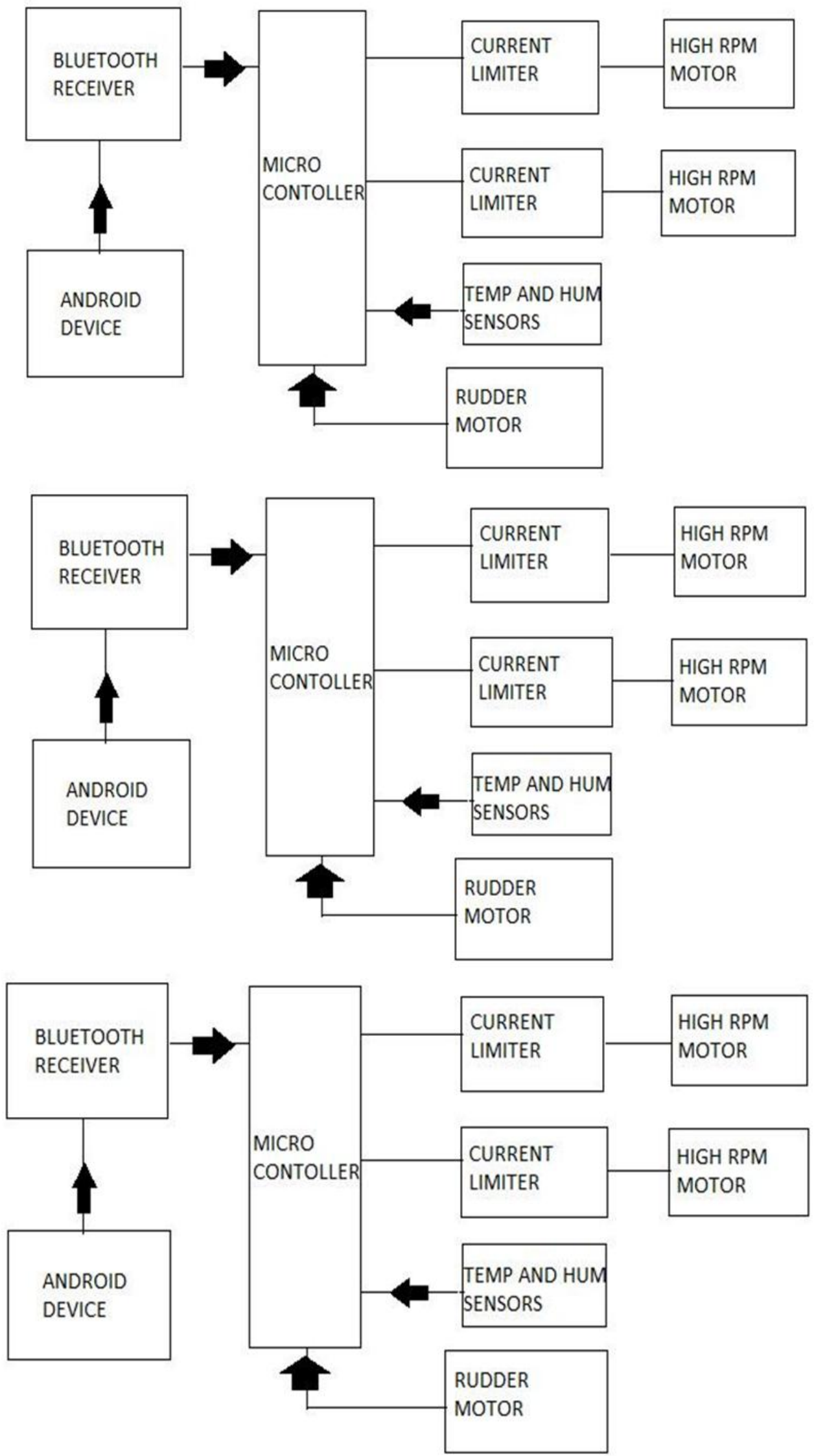

Fig. 1 Block diagram of proposed system 


\section{International Journal of Innovative Research in Electrical, Electronics, Instrumentation and Control Engineering}

\section{ISO 3297:2007 Certified}

Vol. 5, Issue 5, May 2017

\section{BLOCK DESCRIPTION}

A. ATMEGA 328: It is interfaced to the motors of the hovercraft and signal from the android device is passed to the micro controller using Bluetooth connectivity. Micro controller is programmed using embedded $\mathrm{c}$ to work on the received input and control the motors connected to it.

B. ANDROID AND BLUETOOTH: An android phone is used to control the hovercraft. For the purpose an android app is developed to navigate the hovercraft vehicle. Bluetooth connectivity is used to Pair the phone and Microcontroller module

C. HIGH RPM MOTOR: High rpm motor used to pressurize and expand the air bag placed under the hover craft vehicle .this is the preliminary task in start the vehicle. It is interfaced to ATMEGA 328 Microcontroller.

D. RUDDER MOTOR: This motor is used to drive and control the direction of motion of the hover craft.it is also interfaced to the Micro controller

E. HIGH POWER SUPPLY:A power supply is an electronic device that supplies electric energy to an electrical load .The primary function of a power supply is to convert one from of electrical energy to another and as a result, power supplies are sometimes referred to as electric power converter. Some power supplies are discrete, stand -alone devices, where as other are built into larger device along with the load.

F. CURRENT LIMITER: Advanced current interruption technology, utilizing high power Solid-State Current Limiters (SSCL), offers a viable solution to the transmission and distribution system problems caused by high available fault current.

G. TEMPRATURE SENSOR: A temperature sensor is a device that gathers data concerning the temperature from a source and converts it to a form that can be understood either by an observer or another device. These sensors come in many different forms and are used for a wide variety of purposes, from simple home use to extremely accurate and precise scientific use. They play a very important role almost everywhere that they are applied; knowing the temperature helps people to pick their clothing before a walk outside just as it helps chemists to understand the data collected from a complex chemical reaction. By addressing board space and bill of materials (BOM) cost constraints, a microcontroller (MCU) with an integrated temperature sensor can provide a cost-effective, single-chip solution for obtaining temperature data.

H. HUMIDITY SENSOR: A sensor which detects and measures atmospheric humidity. In it, an electrical quantity such as resistance or capacitance varies along with the surrounding humidity, and an output voltage or current corresponding to these fluctuations is produced. A measure of the water vapor content in air. Two common manners of expressing this are absolute humidity and relative humidity.

I. VIDEO SURVEILLANCE SYSTEM: This is an integrated wireless IP Camera solution. It combines a high quality digital Video Camera with network connectivity and a powerful web server to bring clear to your Desktop from anywhere. The basic function of it is transmitting remote video on IP network. The high quality video can be transmitted with 30fps speed on the RF transmitter by using MJPEG hardware compression technology.

\section{SIMULATION RESULT}

\section{PROTEUS}

Proteus is virtual system modelling and circuit simulation software. The suite combines mixed mode SPICE circuit simulation, animated components and microprocessor models to facilitate co-simulation of complete microcontroller based designs.

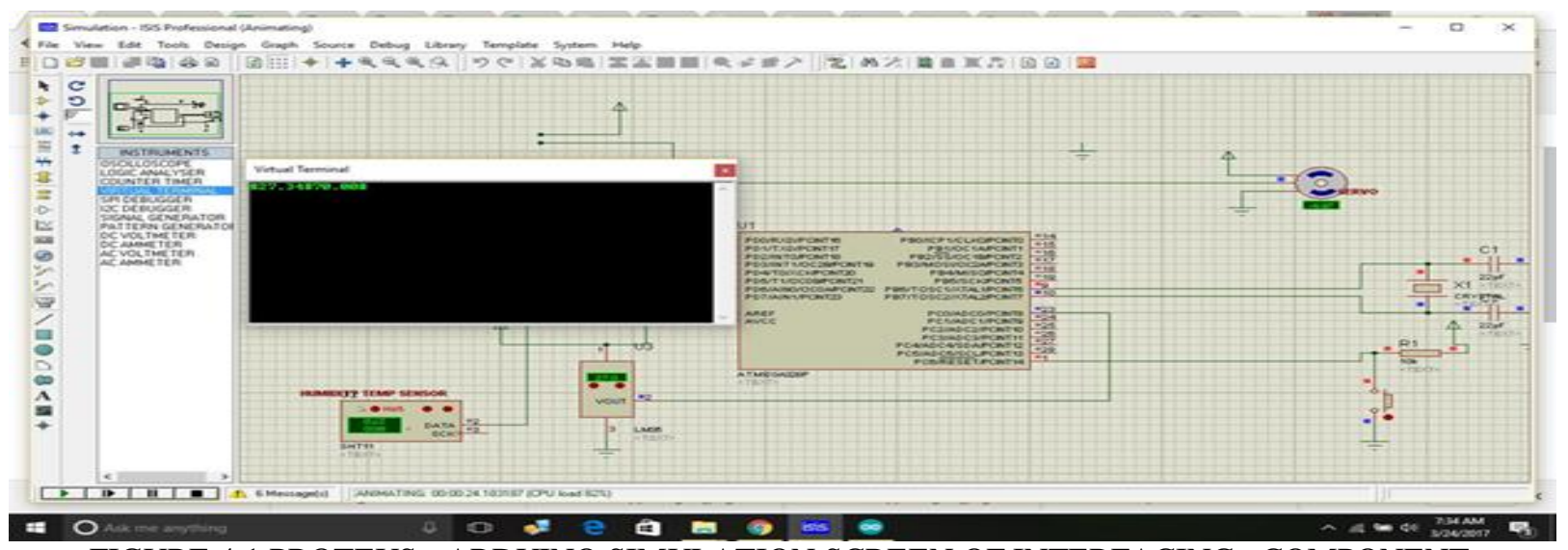

FIGURE 4.1 PROTEUS - ARDUINO SIMULATION SCREEN OF INTERFACING COMPONENT 


\section{IJIREEICE \\ International Journal of Innovative Research in Electrical, Electronics, Instrumentation and Control Engineering \\ ISO 3297:2007 Certified \\ Vol. 5, Issue 5, May 2017}

Proteus also has the ability to simulate the interaction between software running on a microcontroller and any analog or digital electronics connected to it. It simulates input/output ports, interrupts, timers, USARTs and all other peripherals present on each supported processor. It also helps the user to design the PCB for the designed circuit.

\section{ADVANTAGES}

It can be worked over water, land, and other smooth surfaces. It is more maneuverable than boats. It has equivalent operating cost to the conventional boats of the same speed and payload. It is effortless in design, manufacture and operation. It can also be used for transport purposes. It is suitable for Disaster Management and army research operations

\section{DISADVANTAGES}

- They move a lot of air and can be relatively loud.

- Potential of skirt damage.

- More repairs.

- Less capacity.

- Control/stability is less as compared to other vehicles.

\section{APPLICATIONS}

- High speed marine sub surface \& ground scanning survey \& detection.

- Transport, service \& safety craft for river \& low tide coastal work where 24-hour access is vital for staff safety.

- Distribution of famine or flood aid support Relief work.

- Remote mining access support vehicle

\section{CONCLUSION}

The development of air cushion vehicle controlled utilizing android application was fruitful. In the wake of running a few tests to get the best program to work it, the air cushion vehicle could go in any event most of the way around every course. The test was getting the air cushion vehicle to respond at a pace sufficiently quick to keep it moving around the track, yet one moment for that it would be wild. Doing as such took a considerable measure of changing with the heaviness of the air cushion vehicle, the velocity of the fans, and the response time. The main repeating issue that was experienced was the batteries losing control rapidly. The batteries would just permit the air cushion vehicle to run a couple times. To alter that issue the batteries were supplanted with new Neon batteries. Neon batteries ended up being extremely valuable for this anticipate.

\section{ACKNOWLEDGMENT}

The authors would like to acknowledge the Management, Principal, Head of the department, all the faculties and staff of Electronics and Communication Department, of IES College of Engineering, Thrissur, Kerala, for their co-operation and technical guidance given during the entire course of the project work to complete it successfully. We would like to thank all our beloved classmates, friends and family for their encouragement.

\section{REFERENCES}

[1] Mantle, P. J, David W. Taylor, "Air Cushion Craft Development", Naval Ship Research and Development Center, Bethesda, Maryland, DTNSRDC-80/012,1980.

[2] Chung, .1., "Theoretical Investigation of Heave Dynamics of an Air Cushion Vehicle: Bag and Finger Skirt", Ph.D. dissertation. Institute for Aerospace Studies, University of Toronto, 1997

[3] Nah, Seung-Hyeog, "The Development of an Expert System for Aircraft Initial Design (DESAID)", Ph.D. dissertation, Cranfield Institute of Technology, 1991.

[4] Perez, R. E., "Aircraft Conceptual Design Using Genetic Algorithms", 8"' AIAA/USAF/NASA/ISSMO Symposium on Multidisciplinary Analysis and Optimization, AIAA paper No., AIAA-2000-4938, 2000.

[5] Chung, J. and Jung, T., "Optimization of an Air Cushion Vehicle Bag and Finge Skirt Using Genetic Algorithms", Accepted to Journal of Aerospace Science and Technology, Elsevier 2003.

[6] Ryan G. W., "A Genetic Search Technique for Identification of Aircraft Departures” NASA Contractor Report 4688, Dryden Flight Research Center, 1995.

[7] Moran, D.D., “Cushion Pressure Properties of a High Length-to-Beam Ratio Surface Effect Ship,” NSRDC Report SPD-600-01, 1975. 


\section{BIOGRAPHIES}

Clinton A R currently pursuing the Bachelor"s degree in Electronics and Communication Engineering from the IES College of Engineering, Thrissur.

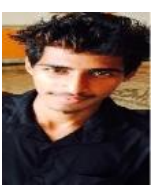

Delvin Lazar currently pursuing the Bachelors degree in Electronics and Communication Engineering from the IES College of Engineering, Thrissur

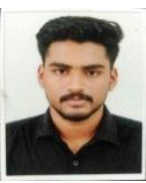

Sarath K M currently pursuing the Bachelors degree in Electronics and Communication Engineering from the IES College of Engineering, Thrissur.

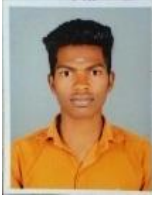

Shibin KK currently pursuing the Bachelor ${ }^{\mathrm{ee}} \mathrm{s}$ degree in Electronics and Communication Engineering from the IES College of Engineering, Thrissur.

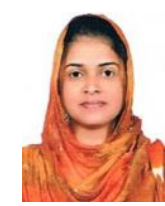

Chitra S Gopi currently pursuing the Bachelors degree in Electronics and Communication Engineering from the IES College of Engineering, Thrissu

Nasheeda V P completed Master"s Degree in Communication Engineering and Signal Processing from MES college of Engineering. She is currently working as Assistant Professor in Department of Electronics and Communication Engineering, IES College of Engineering, Thrissur. 